\title{
Influence of hosts on the production of bioactive compounds in the hemiparasitic plant Helicanthes elasticus
}

\author{
T.G. Ajithkumar', Sinjumol Thomas ${ }^{2}$, Lizzy Mathew ${ }^{3}$ \\ ${ }^{1}$ Government Arts and Science College for Women, Malappuram, Kerala, India \\ ${ }^{2}$ Department of Botany, Carmel College, Mala, Thrissur, Kerala, India \\ ${ }^{3}$ Department of Botany, St.Teresa's College (Autonomous), Ernakulam, Kerala, India \\ *Corresponding author, E-mail: ajithgopalakrishnan81@gmail.com
}

\begin{abstract}
Helicanthes elasticus growing on six different hosts produced different gas chromatograph profiles indicating the influence of host on the metabolite production of parasite. 1,2,3-benzenetriol (pyrogallol) and methyl-3,4,5-trihydroxybenzoate (methyl gallate), which were identified in all of the accessions were considered as gas chromatograph marker compounds of the methanolic extract of the parasite. Some assisted marked compounds obtained from this hemi-parasitic plant and their presence were found to differ among the hosts. Occurrence of various other active ingredients particular to the parasite collected from different hosts were also detected. UPGMA cluster analysis based on the 13 different compounds clearly showed the influence of host on the phytochemical production. Parasitehost interaction leads to phytochemical mosaicism in the selected hemiparasitic plant and such a phenomenon is highly significant for their utilization in various fields of the pharmaceutical industries.
\end{abstract}

Key words: Helicanthes elasticus, hemiparasite, GC-MS, 1,2,3-benzenetriol, methyl-3,4,5-trihydroxybenzoate.

Abbreviations: GC, gas chromatography; HEA, H. elasticus obtained from Anacardium occidentale; HEC, H. elasticus obtained from Citrus maxima; HEH, H. elasticus obtained from Hevea brasiliensis; HEM, H. elasticus obtained from Murraya koenigii; HEN, H. elasticus obtained from Nerium oleander; HES, H. elasticus obtained from Saraca asoca; MS, mass spectrometry; RT, retention time.

\section{Introduction}

Loranthaceae, the most widely dispersed family of parasitic plants known as mistletoes, has been afflicted by alarming rates of generic and specific level misidentification (Franklin 2017). They are primarily pantropical in distribution, with a range that includes temperate zones in the southern hemisphere (Rajasekaran 2007). The family is particularly interesting because it is a monophyletic group that comprises both terrestrial and aerial root parasites (Wilson, Calvin 2006). Furthermore, despite being a minor component of vegetation in forest and woodland ecosystems, mistletoe has a significant impact on species richness and is regarded as a keystone resource (Watson 2001). Loranthaceae has over 1000 species in 74 genera and is primarily distributed in tropical areas (Barlow et al. 1989). In India, Loranthaceae comprises nine genera and 35 species with Dendrophthoe, Helicanthes, Macrosolen, Tolypanthes, Helixanthera, Taxillus, and Scurulla being the most extensively spread in South India (Thriveni 2013).

Helicanthes elasticus (Desv.) Danser is a robust parasite with dichotomous branching and subsessile and decussate leaves. Flowers are produced in short axillary fascicles with a very small bract. Their calyx is cupular and corolla lobes are twisted and interlocked after anthesis. Flowers often produce five stamens with narrowly oblong anthers. The style is linear and stigma obovoid. The fruit is a globose berry. The branches are woody and are swollen at nodes (Sasidharan, Sivarajan 1996). It is one of the most delicate mistletoes, and can grow rapidly over the host. When infested, it produces a number of haustoriferous runners or epicortical roots from its base to all sides. Within a short period, the parasite creates a network over the host and it branches profusely, which helps the mistletoe to establish even on the vertical smooth trunks of trees. The dead parasite can be distinguished by the netlike haustorial growth, dichotomous branching and swollen nodes (Shanavaskhan, Sivadasan 2009). H. elasticus is a generalist parasite having a capacity to grow on diversified plant species including angiosperms and gymnosperms.

Among the members of Loranthaceae found in Kerala, this parasitic species showed maximum diversity in the number of host trees. A wide variety of plants were infected by this Loranthacean member and each host plant might have some influence on the growth pattern of this parasite. Nearly 73 trees belonging to different families were already reported as hosts of this plant (Sunil Kumar et al. 2015; Ajith Kumar, Mathew 2020). It was reported by Scot (1871) that 
trees with bark having acrid, bitter or astringent qualities, and which produce limbid or milky juice, are less affected by Loranthacean members. However, the plant H. elasticus can infest the latex-producing Hevea brasiliensis, volatile oilcontaining Citrus species (Shanavaskhan, Sivadasan 2009) and heavy barked trees like Terminalia (Sunil Kumar et al. 2015). The morphology, anatomical features, physiological behavior, phytochemical content or even genetic makeup of the parasite could be affected by the host. There are citations in famous Ayurvedic literature about the mistletoes. It was mentioned by Susrutha (ancient Indian physician known today as Father of Surgery) that the properties of this parasitic plant varies between hosts. Also, Raja Nighantu, an ancient Ayurvedic work by Narahari, states that along with the phytochemical properties of the mistletoe, it also shows the properties of host plant in which they grow (Namboothiri 2011). Influence of the host plant on the chemical composition of mistletoe and dependence of its medicinal properties on the host species were shown in the case of Dendrophthoe falcata (Indrani, Balasubhramanian 1985). It was reported that D. falcata grown on Calotropis gigantea improved cognitive function (Warrier et al. 1996) and the same plant infected on Shorea robusta was found to be effective in the treatment of paralysis, and the plant obtained from Tamarindus indica was used for treating impotency (Jain,1965). The importance of the host's function in the production of biologically active substances by the parasitic plants growing was well explained by these findings.

The major aim of the present study was to analyze the role of host tree in the production of biologically significant compounds in $\mathrm{H}$ elasticus. For this, gas chromatographymass spectrometry (GC-MS) was used to determine the differences in the occurrence of such compounds in this hemi-parasitic plant collected from six different hosts. Mass spectroscopy (MS) coupled with gas chromatography (GC) can detect compounds and is used for direct analysis of chemical components present in herbal medicine. It has proved to be highly suitable for the analysis of nonpolar components, volatile essential oils, fatty acids, lipids and alkaloids (Betz et al. 1997). Various chemical compounds eluted in the extraction process were identified and quantified based on their retention value and with matching spectra. MS analyzes the compounds eluted at different times to identify their nature and structure. The large compounds break into smaller ones giving different peaks at different $\mathrm{m} / \mathrm{z}$ ratios. The fingerprint obtained from the analysis consists of different peaks, each denoting a specific compound and the height of the peaks determines their quantity. The fingerprint is the GC chromatogram for a particular extract of a plant, it is unique and hence can be used for the correct identification and authentication of a particular plant or drug. Comparison of the chromatogram and eluted compounds serves as an effective tool to analyze the influence of hosts on them.

\section{Materials and methods}

\section{Plant material}

Fresh and tender twigs of Helicanthes elasticus growing on six host plants (Nerium oleander, Hevea braziliensis, Citrus maxima, Saraca asoca, Anacardium occidentale and Murayya koeinigii) were collected from various sites places of the Ernakulam District $\left(10.0718^{\circ} \mathrm{N}, 76.5488^{\circ} \mathrm{E}\right)$, Kerala, India. The branches of the hosts affected with parasite were also collected at a distance of $50 \mathrm{~cm}$ from the point of infection. Both the hosts and parasites collected were identified using reference books (Gamble 1967; Sasidharan, Sivarajan 1996; Nayar et al. 2006). Specimens of $H$. elasticus collected from selected hosts were entered in the herbarium of the Department of Botany, St. Teresa's College (Autonomous), Ernakulam, Kerala. Twigs of $H$. elasticus collected from above six host plants were shade dried for a month and powdered.

\section{Extract preparation}

A sample of $20 \mathrm{~g}$ powder of parasitic accessions was extracted in $200 \mathrm{~mL}$ methanol for $10 \mathrm{~h}$ in a Soxhlet apparatus and the extract was concentrated to $10 \mathrm{~mL}$ using a rotary evaporator, $2 \mathrm{~mL}$ of each were stored in cuvettes and used for GC-MS analysis.

\section{GC-MS analysis}

The GC-MS analysis of the extract was performed using a model QP 2010 series Shimadzu, Tokyo, Japan equipped with a Rxi-5Sil MS fused silica capillary column of $30 \mathrm{~m}$ length, $0.25 \mathrm{~mm}$ diameter and $0.25 \mu \mathrm{m}$ film thickness. Helium gas was used as the carrier gas at a constant flow rate of $1 \mathrm{~mL} \mathrm{~min}^{-1}$ and $1 \mu \mathrm{L}$ of the sample was manually injected in split mode. Injection temperature was set at 200 ${ }^{\circ} \mathrm{C}$, at a flow control mode in linear velocity of $36.3 \mathrm{~cm} \mathrm{~s}^{-1}$. The oven temperature was programmed from 50 to $280^{\circ} \mathrm{C}$ at a rate of $5^{\circ} \mathrm{C} \mathrm{min}{ }^{-1}$ increase and retained for about $5 \mathrm{~min}$ at the end. The total running time of the GC-MS was 51 min. MS parameters were $200{ }^{\circ} \mathrm{C}$ ion source temperatures and $280^{\circ} \mathrm{C}$ interface temperatures.

Identification of the components in the extracts was assigned by the comparison of their retention indices and mass spectra fragmentation patterns with those stored in the computer library and also with published literature. The relative amount of each compound in percentage was determined by comparing its average peak area to total area. The NIST011s.LIB, WILEY8 LIB library source was used for matching the identified components from the plant materials. This was carried out in order to determine whether the species contain group of compounds or any individual compound that gives proof for its use in current commercial and tradition as a herbal medicine (Manickam, Periyasami 2014). 


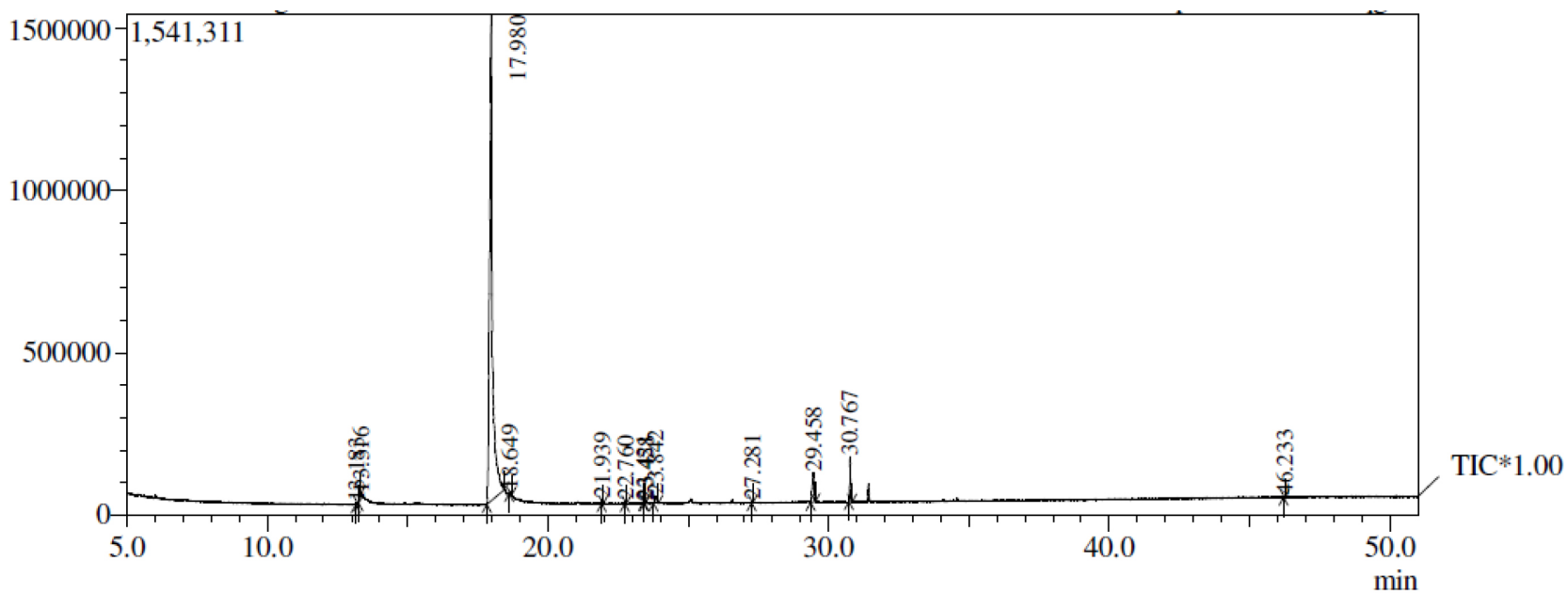

Fig. 1. GC chromatogram of H. elasticus growing on Nerium oleander (HEN).

\section{Dendrogram construction}

Based on the comparative analysis of selected chemical compounds identified in parasitic samples, a Jaccard's similarity index table was produced and an UPGMA tree was constructed based on this index to determine the similarity among the six accessions of $H$. elasticus obtained from six different hosts

\section{Results}

H. elasticus growing on Nerium oleander (HEN) produced 13 peaks in the chromatogram (Fig. 1) representing 13 different compounds; 1,2,3-benzenetriol with retention time (RT) value 17.980 had a maximum area percentage of 91.76, while the other peaks found were relatively small and had a lower area (Table 1). The parasite on Hevea brasiliensis showed the occurrence of 21 different peaks (Fig. 2) and 1,2,3-benzenetriol (74.88\%) and 1,3,4,5-tetrahydroxycyclohexane carboxylic acid (10.13\%) were the most prominent compounds. Other biologically active compounds like hexadecanoic acid, 1,2-benzenediol and nonanoic acid were also present in the H. elasticus growing on Hevea brasiliensis (Table 2). The H. elasticus parasitic on Citrus maxima showed 10 peaks with 1,2,3-benezenetriol having the largest area percentage (68.65\%) and having RT of 18.036 (Fig. 3, Table 3).

H. elasticus grown on Saraca asoca showed 18 peaks (Fig. 4) of which the largest area percentage was shown by $1,2,3$ benzenetriol with $51.59 \%$ and RT 17.958 , followed by 1,3,4,5-tetrahydroxy-cyclohexane carboxylic acid with $33.40 \%$ and RT 24.191. Other important compounds found in the extract of the parasite were 1,2-benezenediol, diglycerol, hexadecanoic acid, oxalic acid etc. (Table 4). $H$. elasticus obtained from Anacardium occidentale produced 16 peaks (Fig. 5), of which 1,2,3-benzenetriol formed the main compound with $63.36 \%$ area, followed by $1,3,4,5$ tetrahydroxy-cyclohexane carboxylic acid with $26.67 \%$. Brenzkatechin, 2-amino-succinamic acid, thymine, etc. were also present in the extract (Table 5). Analysis of $H$. elasticus growing on Murayya koeinigii (HEM) showed 23

Table 1. GC-MS peak report of methanolic extract of $H$. elasticus obtained from Nerium oleander (HEN) with compounds detected

\begin{tabular}{lllc} 
Peak No. & RT & Compound & Area (\%) \\
\hline 1 & 13.183 & N-methyl-N-aminosulfonyl-N-methylsulfonylamine & 0.09 \\
\hline 2 & 13.316 & 1,2 -Benzenediol & 0.47 \\
\hline 3 & 17.980 & $1,2,3$-Benzenetriol & 91.76 \\
\hline 4 & 18.649 & Cyclohexanone, dimethylhydrazone & 0.10 \\
\hline 5 & 21.939 & Nonanoic acid, methyl ester & 0.29 \\
\hline 6 & 22.760 & 1-Butanol, 3-methyl- & 0.10 \\
\hline 7 & 23.421 & 3-Nitropentan-2-ol & 0.13 \\
\hline 8 & 23.458 & Isobutyl alcohol-2-d1 & 0.06 \\
\hline 9 & 23.842 & Butyric acid, 3-methylbutylester & 1.08 \\
\hline 10 & 27.281 & Butanoic acid & 0.10 \\
\hline 11 & 29.458 & Methyl 3,4,5-trihydroxybenzoate & 3.34 \\
\hline 12 & 30.767 & Hexadecanoic acid, methyl ester & 2.43 \\
\hline 13 & 46.233 & Ethyne, fluoro- & 0.04 \\
\hline
\end{tabular}




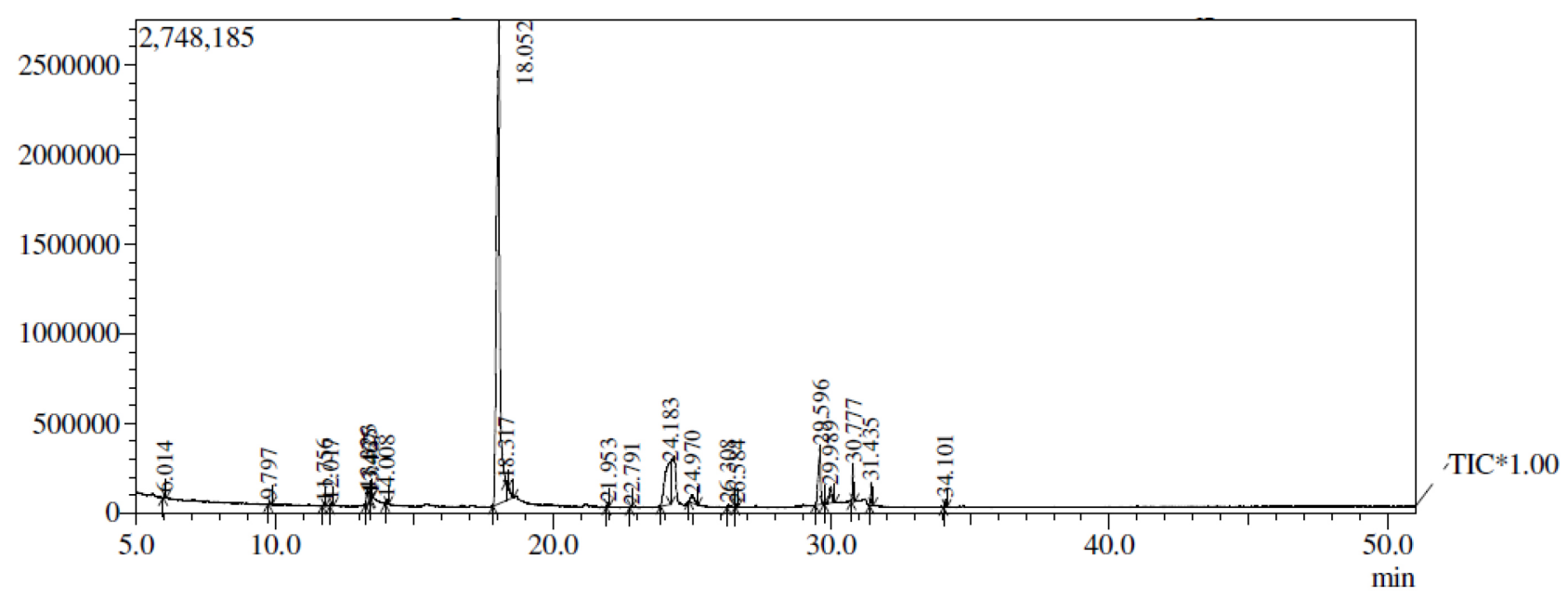

Fig. 2. GC chromatogram of H. elasticus growing on Hevea brasilensis (HEH).

different peaks (Fig. 6) with 1,2,3-benzenetriol being the main compound with RT 17.955 and $62.74 \%$ area. Other important compounds indicated included 1,2-benzenediol, 2-heptamine, propiolic acid, hexadecanoic acid, acetic acid, nitrous acid, heptadecanoic acid, butanoic acid etc. (Table 6).

An UPGMA tree was produced based on the Jaccard's similarity index. It classified the six accessions of $H$. elasticus collected from six different host plants into three clusters (Fig. 7). Cluster I comprised HEN and HEH, Cluster II with HEC and HEM and Cluster III with HES and HEA. The accessions of Cluster II showed maximum similarity of
77\% with Cluster III in the bioactive compounds obtained (Table 7) with GC-MS. Cluster I formed a separate branch in the tree and was joined to the other clusters with more similarity with accessions of Cluster II.

\section{Discussion}

Parasitic plants, especially the obligate hemiparasites mistletoes, depend on hosts for water and nutrients and differ in their host use preference and specificity (Calder, Bernhardt 1983; Press, Graves 1995). Apart from this, chemical signalling or specific chemical interactions occur

Table 2. GC-MS peak report of methanolic extract of H. elasticus obtained from Hevea brasiliensis (HEH) with compounds detected

\begin{tabular}{llll}
\hline Peak No. & RT & Compound & Area (\%) \\
\hline 1 & 6.014 & 2,3-Dihydroxy propanal & 0.20 \\
\hline 2 & 9.797 & Methoxy cyclobutane & 0.14 \\
\hline 3 & 11.756 & 2,3 -Dihydro-3,5-dihydroxy-6-methyl-4H-pyran-4-one & 0.16 \\
\hline 4 & 12.017 & Formic acid, ethenyl ester & 0.21 \\
\hline 5 & 13.323 & 1,2 -Benzenediol & 1.51 \\
\hline 6 & 13.425 & p-Mesyloxyphenol & 0.17 \\
\hline 7 & 13.467 & 2-Furancarboxaldehyde, 5-methyl- & 0.12 \\
\hline 8 & 14.008 & 2-Furancarboxaldehyde, 5-(hydroxymethyl)- & 0.20 \\
\hline 9 & 18.052 & $1,2,3$-benzenetriol & 74.88 \\
\hline 10 & 18.317 & Hexane-1,6-bisurea, n', n"-bis(1,2,4-triazol-3-yl)- & 0.04 \\
\hline 11 & 21.953 & Tetradecanoic acid, 12-methyl-, methyl ester & 0.14 \\
\hline 12 & 22.791 & Propanedioic acid, propyl- & 0.09 \\
\hline 13 & 24.183 & $1,3,4,5-$ Tetrahydroxy-cyclohexanecarboxylic acid & 10.13 \\
\hline 14 & 24.970 & D-glycero-D-galacto-heptose & 1.17 \\
\hline 15 & 26.308 & 1-Butanol, 3-methyl- & 0.25 \\
\hline 16 & 26.584 & Nonanoic acid, methyl ester & 0.12 \\
\hline 17 & 29.596 & Methyl 3,4,5-trihydroxybenzoate & 5.80 \\
\hline 18 & 29.989 & Beta-D-glucopyranose, 1,6-anhydro- & 1.87 \\
\hline 19 & 30.777 & Hexadecanoic acid, methyl ester & 1.48 \\
\hline 20 & 31.435 & Hexadecanoic acid & 0.93 \\
\hline & 34.101 & Methyl-9-octadecenoate & 0.40 \\
\hline
\end{tabular}




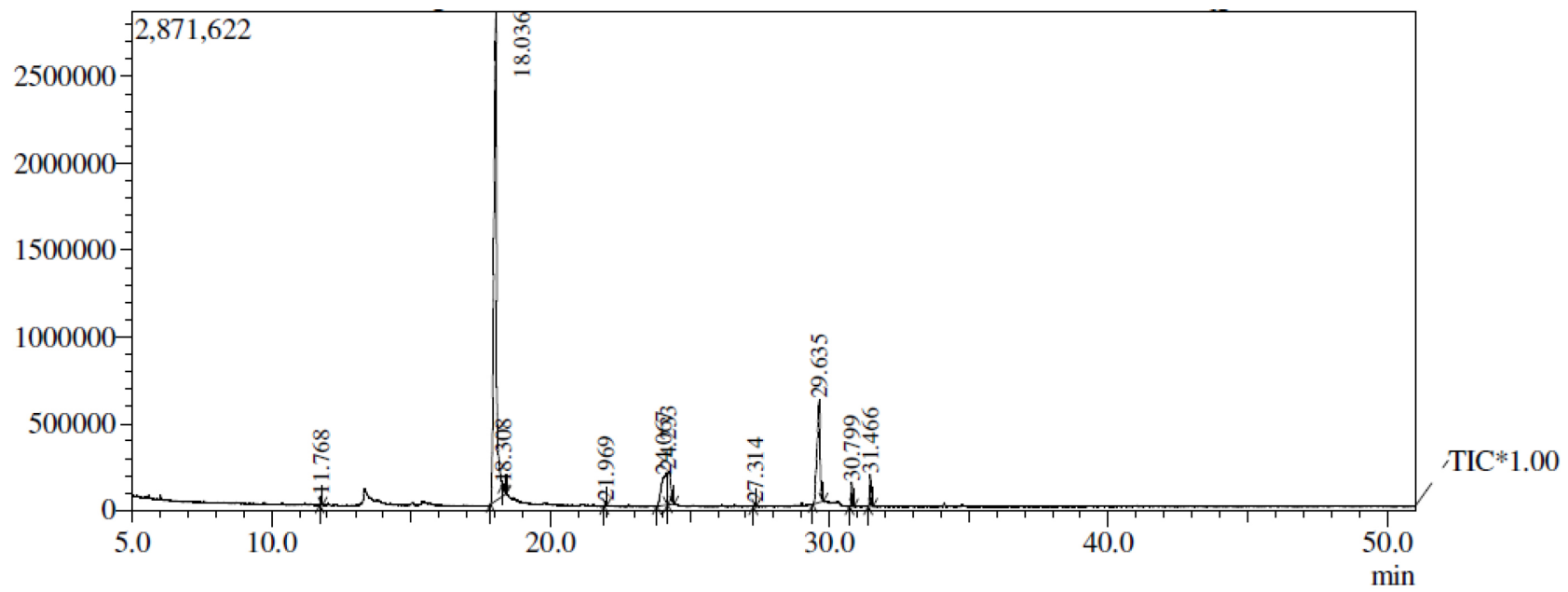

Fig. 3. GC chromatogram of H. elasticus growing on Citrus maxima (HEC).

Table 3. GC-MS peak report of methanolic extract of H. elasticus obtained from Citrus maxima (HEM) with compounds detected

\begin{tabular}{lllc} 
Peak No. & RT & Compound & Area (\%) \\
\hline 1 & 11.768 & 2,3-Dihydro-3,5-dihydroxy-6-methyl-4H-pyran-4-one & 0.43 \\
\hline 2 & 18.036 & $1,2,3$-Benzenetriol & 68.65 \\
\hline 3 & 18.308 & Methyl 5-oxo-2-pyrrolidinecarboxylate & 0.10 \\
\hline 4 & 21.969 & Undecanoic acid, methyl ester & 0.20 \\
\hline 5 & 24.067 & $1,3,4,5$-Tetrahydroxy-cyclohexanecarboxylic acid & 8.42 \\
\hline 6 & 24.233 & $1,3,4,5$-Tetrahydroxy-cyclohexanecarboxylic acid & 4.31 \\
\hline 7 & 27.314 & Decanoic acid & 0.16 \\
\hline 8 & 29.635 & Methyl 3,4,5-trihydroxybenzoate & 15.12 \\
\hline 10 & 30.799 & Hexadecanoic acid, methyl ester & 1.03 \\
\hline
\end{tabular}

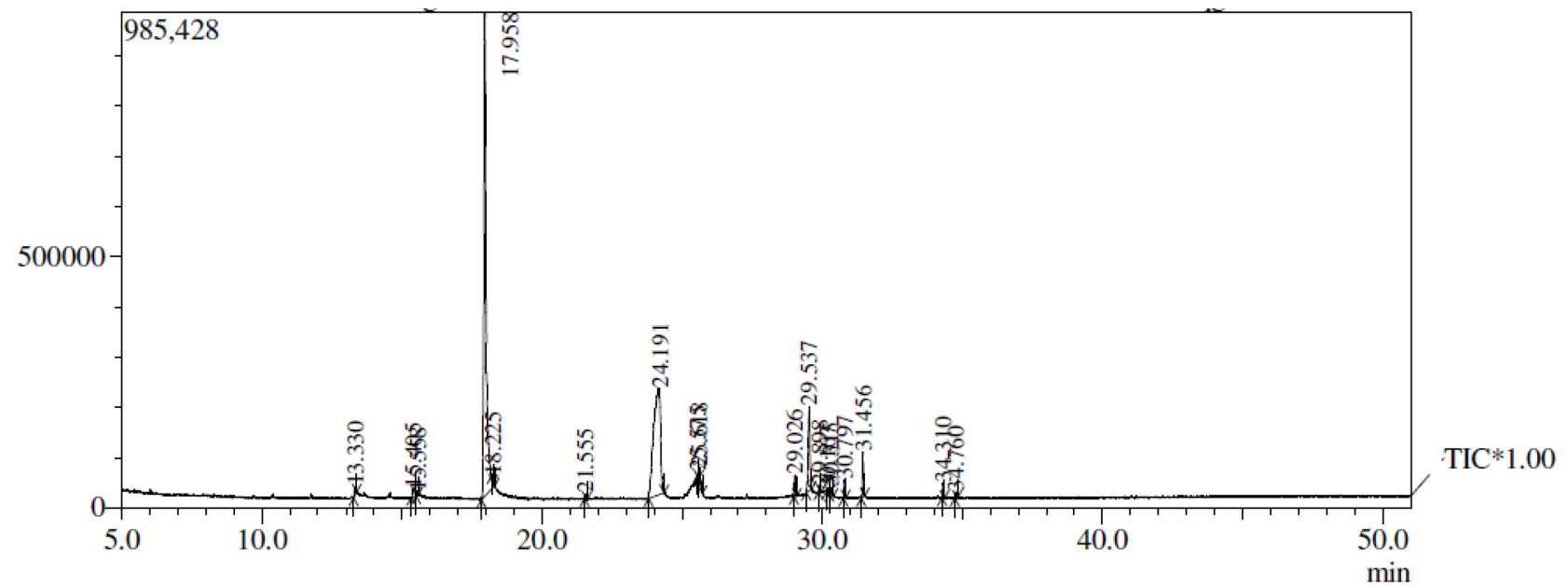

Fig. 4. GC chromatogram of H. elasticus growing on Saraca asoca (HES).

between mistletoes and their hosts as they require contact signals to recognize a host to initiate the development of the haustorium for its establishment (Desale et al. 2016). Such factors are called haustorium-inducing factors (Jamison, Yoder 2001). Some require chemical signals such as strigolactones for germination of their seeds on the host surface (Xie et al. 2010; Cavar et al 2015). It was reported that haustorium-inducing factors might be species specific and activate specific recognition sites in particular parasites or host plants, which leads to paratite establishment (Tomilov et al. 2006).

The host-parasitic interaction is an ongoing process 
Table 4. GC-MS peak report of methanolic extract of H. elasticus obtained from Saraca asoca (HES) with compounds detected

\begin{tabular}{lllc} 
Peak No. & RT & Compound & Area (\%) \\
\hline 1 & 13.330 & 1,2-Benzenediol & 0.60 \\
\hline 2 & 15.405 & 2,5-Cyclohexadiene-1,4-dione compound with 1,4-benzenediol & 1.04 \\
\hline 3 & 15.558 & 7-Oxa-1-azabicyclo[3.2.1] octane, 5-methyl- & 0.20 \\
\hline 4 & 17.958 & $1,2,3$-Benzenetriol & 51.59 \\
\hline 5 & 18.225 & 1-Proline, 5-oxo-, methyl ester & 0.08 \\
\hline 6 & 21.555 & 2-Tert-butyl-4-(1,1,3,3-tetramethylbutyl) phenol & 0.19 \\
\hline 7 & 24.191 & 1,3,4,5-Tetrahydroxy-cyclohexanecarboxylic acid & 33.40 \\
\hline 8 & 25.575 & Diglycerol & 0.13 \\
\hline 9 & 25.618 & Mome inositol & 0.91 \\
\hline 10 & 29.026 & Butanoic acid, 3,7-dimethyl-6-octenyl ester & 0.92 \\
\hline 11 & 29.537 & Methyl 3,4,5-trihydroxybenzoate & 6.18 \\
\hline 12 & 29.898 & 9-Dodecen-1-ol (Z)- & 0.23 \\
\hline 13 & 30.167 & Oxalic acid, cyclobutyl ethyl ester & 0.29 \\
\hline 14 & 30.315 & Dodecanoic acid & 0.57 \\
\hline 15 & 30.797 & Tetradecanoic acid, 12-methyl-, methyl ester & 0.69 \\
\hline 16 & 31.456 & Hexadecanoic acid & 2.07 \\
\hline 17 & 34.310 & Cyclohexanol, 5-methyl-2-(1-methylethyl) & 0.59 \\
\hline 18 & 34.760 & 4-Pentenal, 2,2-dimethyl & 0.30 \\
\hline
\end{tabular}

that alters the chemical profile of both hosts and parasite. Differences in the number of phytochemical components, colour and health-promoting properties found altered in parasitic plants depend on the host on which it is parasitic and on the particular organs of the parasite (Renata et al 2020). Stem parasitic plants show different metabolic profiling and changes during parasitization and such differences are reflected in their life style and morphology (Takeshi et al. 2016)

In the present study the GC chromatograms and peaks obtained from the methanolic extract of $H$. elasticus accessions differed depending on the host. All of the eluted compounds were carefully examined and it was found that 13 different compounds could be considered as the products of $H$. elasticus and that their relative occurrence in different parasitic accessions was greatly influenced by the respective hosts (Table 8). Among these, two compounds were considered as marker compounds of the parasite, whereas some were recognized as assisted marker compounds that did not occur in all samples of $H$. elasticus, but were solely of parasitic origin. The presence of these assisted marker compounds was greatly influenced by the hosts species. 1,2,3-benzenetriol (pyrogallol) and methyl-3,4,5-tri-hydroxybenzoate (methylgallate) were the two major compounds found in all samples of $H$. elasticus, irrespective of their host and these two were the marker compounds of the methanolic extract of the parasite. The weight percentage ratio of these marker compounds found also varied among the host plants. The largest quantity of pyrogallol was obtained in HEN and least from HEC, whereas methyl gallate occurred in highest amount in the accession HEC and least in HEN. Other accessions

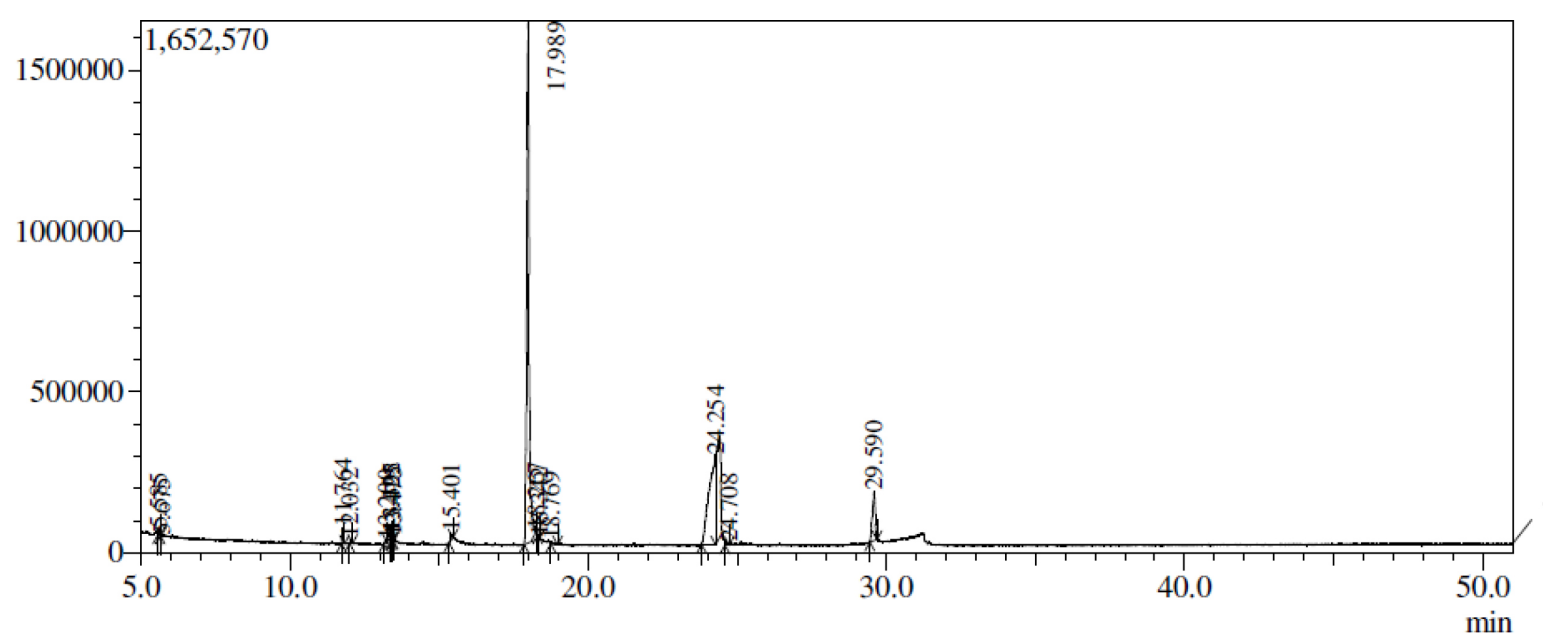

TIC* 1.00

Fig. 5. GC chromatogram of $H$. elasticus growing on Anacardium occidentale (HEA). 
Table 5. GC-MS peak report of methanolic extract of $H$. elasticus obtained from Anacardium occidentale (HEA) with compounds detected

\begin{tabular}{lllc} 
Peak No. & RT & Compound & Area (\%) \\
\hline 1 & 5.585 & $2(3 \mathrm{H})$-Furanone & 0.34 \\
\hline 2 & 5.675 & Propanedioic acid & 0.05 \\
3 & 11.764 & 2,3 -Dihydro-3,5-dihydroxy-6-methyl-4H-pyran-4-one & 0.77 \\
\hline 4 & 12.032 & Delta(1,1')-biurea & 0.24 \\
\hline 5 & 13.200 & Brenzkatechin & 0.22 \\
\hline 6 & 13.392 & (CH3)3CD & 0.47 \\
\hline 7 & 13.425 & 2 -Amino-succinamic acid & 0.22 \\
\hline 8 & 13.475 & Trifluoro-ethene & 0.06 \\
\hline 9 & 15.401 & 2,5 -Cyclohexadiene-1,4-dione compound with 1,4-benzenediol & 0.60 \\
\hline 10 & 17.989 & $1,2,3$-Benzenetriol & 63.36 \\
\hline 11 & 18.267 & Alpha-aminoisobutyronitrile & 0.00 \\
\hline 12 & 18.342 & Thymine & 0.01 \\
\hline 13 & 18.769 & 2,5 -Cyclohexadiene-1,4-dione compound with 1,4-benzenediol & 0.19 \\
\hline 14 & 24.254 & $1,3,4,5$-Tetrahydroxy-cyclohexanecarboxylic acid & 26.67 \\
\hline 15 & 24.708 & (CH3)3CD & 0.34 \\
\hline
\end{tabular}

also showed a large area percentage for these compounds. Both these compounds are phenolic derivatives that likely have a crucial role in parasitic adaptations. Converting surface phenolics to benzoquinons by parasitic derived oxidase enzymes acts as developmental signals for the transition from vegetative to parasitic growth (Kim et al. 1998). It has also been reported that a wide range of simple phenols can cause the establishment of haustoria in parasitic Scrophulariaceae members (Lynn, Chang 1990; Chang, Lynn 1986). The compound 1,3,4,5-tetrahydroxy cyclohexane carboxylic acid was also detected in all parasite sample except HEN. This compound was detected in its host Nerium oleander. The following compounds were found in all parasite accessions with the exception of those given in brackets: 1,2 benzenediol (except in HEC and HEA), hexadecanoic acid (except in HEN and HEA) and 2,3-dihydro-3,5-dihydroxy-6-methyl-4H-pyran-4one (except in HEN and HES). Among these compounds hexadecenoic acid was detected in Citrus maxima (the host of HEC) and 2,3-dihydro-3,5-dihydroxy-6-methyl$4 \mathrm{H}$-pyran-4-one in three host species: Nerium oleander, Citrus maxima and Anacardium occidentale. Absence of some of these compounds in hemi-parasitic plant samples collected from different hosts might be due to the hindrance in their production by the respective hosts. The marker compound 1,2,3-benzenetriol of the parasite found in the host plants Hevea brasiliensis, Saraca asoca and Anacardium occidentale could be derived from the attached parasite $H$. elasticus. Similarly, hexadecanoic acid and 2,3-dihydro-3,5-dihydroxy-6-methyl-4H-pyran-4-one are also transported from the parasite to the respective hosts. Absence of these compounds in some samples of

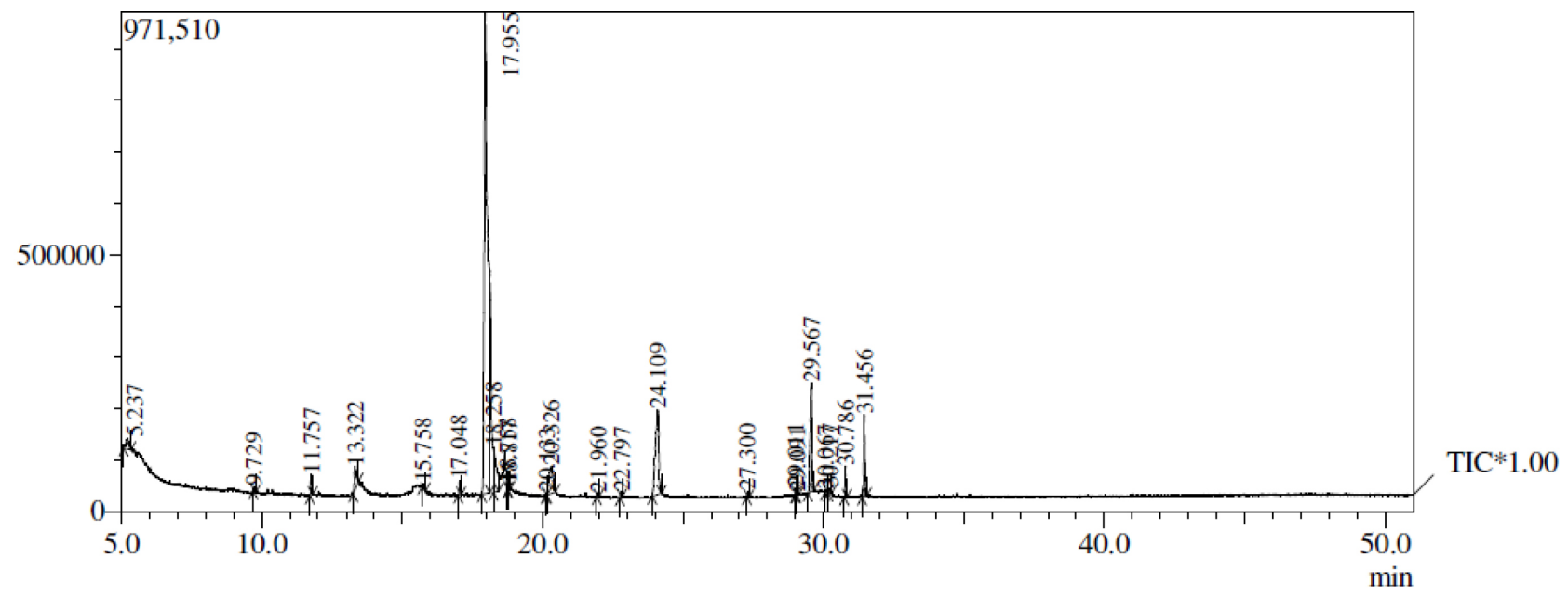

Fig. 6. GC chromatogram of H. elasticus growing on Murraya koenigii (HEM). 
Table 6. GC-MS peak report of methanolic extract of $H$. elasticus obtained from Murraya koenigii (HEA) with compounds detected

\begin{tabular}{lllc} 
Peak No. & RT & Compound & Area (\%) \\
\hline 1 & 5.237 & Propiolic acid & 1.34 \\
\hline 2 & 9.729 & Ethyl 6-oxo-5-propylheptanoate & 0.19 \\
\hline 3 & 11.757 & 2,3-Dihydro-3,5-dihydroxy-6-methyl-4h-pyran-4-one & 0.80 \\
\hline 4 & 13.322 & 1,2-Benzenediol & 1.95 \\
\hline 5 & 15.758 & Butyl 1-methyl-2-pyrrolidinecarboxylate & 0.10 \\
\hline 6 & 17.048 & 1-Proline, 1-methyl-5-oxo-, methyl ester & 0.54 \\
\hline 7 & 17.955 & 1,2,3-Benzenetriol & 62.74 \\
\hline 8 & 18.258 & Methyl 5-oxo-2-pyrrolidinecarboxylate & 4.53 \\
\hline 9 & 18.758 & 3-Butyn-2-ol & 0.11 \\
\hline 10 & 18.817 & 2-Heptanamine & 0.17 \\
\hline 12 & 20.326 & Pyrrolin-2-one-5-methanol, N-methyl- & 4.08 \\
\hline 13 & 21.960 & Methyl 6-hydroxycaproate & 0.14 \\
\hline 14 & 22.797 & Propane, 2-methoxy-2-methyl & 0.21 \\
\hline 15 & 24.109 & 1,3,4,5-Tetrahydroxy cyclohexanecarboxylic acid & 10.92 \\
16 & 27.300 & Nitrous acid, 3-methyl butyl ester & 0.22 \\
\hline 17 & 29.011 & 1-Acetyl-1H-pyrazole & 0.16 \\
\hline 18 & 29.091 & Butanoic acid & 0.04 \\
\hline 19 & 29.567 & Methyl 3,4,5-trihydroxybenzoate & 6.97 \\
\hline 20 & 30.067 & Acetic acid, cyano- & 0.21 \\
\hline 21 & 30.217 & 2-Methyl-5-hexen-3-ol & 0.26 \\
\hline 22 & 30.786 & Heptadecanoic acid, methyl ester & 1.03 \\
\hline 23 & 31.456 & Hexadecanoic acid & 3.22 \\
\hline
\end{tabular}

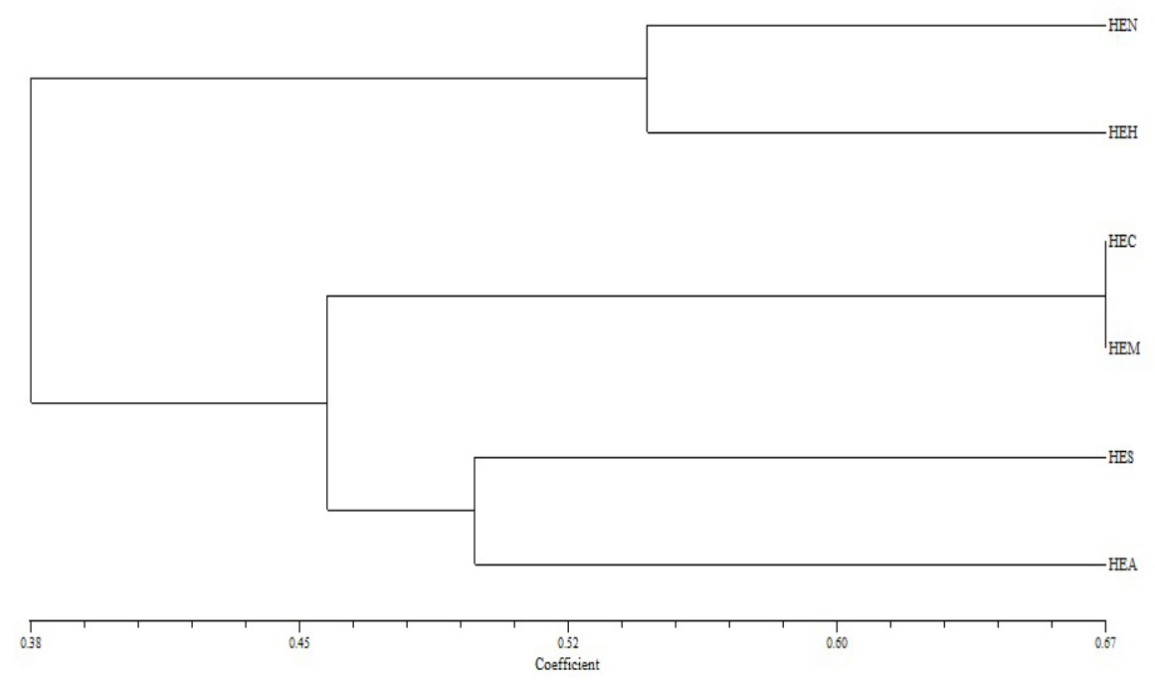

Fig. 6. Jaccard's UPGMA tree based on the occurrence of 13 compounds among six accessions of Helicanthes elasticus.

Table7. Jaccard's similarity matrix based on the occurrence of 13 compounds among six accessions of H. elasticus

$\begin{array}{lllllll} & \text { HEN } & \text { HEH } & \text { HEC } & \text { HES } & \text { HEA } & \text { HEM } \\ \text { HEN } & 1 & & & & & \\ \text { HEH } & 0.615 & 1 & & & & \\ \text { HEC } & 0.385 & 0.62 & 1 & 1 & 1 & \\ \text { HES } & 0.385 & 0.62 & 0.54 & 0.69 & 1\end{array}$


H. elasticus might be due to the influence of hosts during the establishment of parasite. Such cases were previously reported in the holoparasitic plant Cuscuta reflexa in which GC-MS analysis the plant obtained from two hosts Cassia fistula and Ficus benghalensis differed in phytochemical constituents (Bais, Kakkar 2013; Bais, Kakakr 2014). Region dependent variation in phytoconstituents was also reported in ethanolic extract of Cuscuta reflexa assessed by GC-MS (Rai et al. 2016). Marked variation in secondary metabolites also occurred in the ethanolic bark extract of Loranthus longiflorus growing on Casuarina equisetifolia and Ficus religiosa (Chandrakasan, Neelamegham 2011a) and Ficus religiosa had greater tannin content in bark samples of Loranthus longiflorus than Casuarina equisetifolia (Chandrakasan, Neelamegham 2011b).

Transfer of specific compounds from parasite to host cells could be considered as a suppressing signal molecule that suppresses the so-called immune system of the host plant such that the parasite can establish within the hosts. Resistant host plants detect parasite molecules for immune system activation to eradicate the parasite, while the parasitic derived compounds have virulence functions such as host immunity suppression (Saucet, Shirasu 2016). Such a dynamic nature of adaptation often leads to co-evolution among the partners of the interaction and thereby leads to speciation. During such host-parasitic interactions, some chemical molecules might be transferred from parasite to hosts and hence such molecules would not be get detected in parasite samples. 1,3,4,5 tetrahydroxy cyclohexane carboxylic acid and 2,3-dihydro-3,5-dihydroxy-6methyl-4H-pyran-4-one played such a role in H. elasticus growing on Nerium oleander, which can explain why these compounds were completely absent in the parasite but detected in the host plant. These compounds might get transported from the parasite to the host as soon as it was synthesized through the haustoria as a chemical signal that supported the parasite's survival on the particular host by reducing its fitness. The exchange of potential defense signalling molecules between host and parasite through a haustorial interface is well established in many parasitic plants (Christopher et al. 2019). Chemical signals in the form of cytokinin-like compounds were reported to be transported from the parasitic plant Phtheirospermum japonicum to its host Arabidopsis thaliana to reduce host fitness and thereby ensure well establishment of parasite within the host (Thomas et al. 2017). It was reported that presence of certain secondary metabolites that differ within a population of hemiparasites depend upon the host-parasitic association (Stermitz, Harris 1987). In Nerium oleander, the above mentioned chemical might have a suppressing role on the plants defense mechanism to eliminate the parasite, acting as an immunosuppressant in a human during organ transplantation, allowing the parasite to establish on Nerium oleander. Host susceptibility to parasite attack could result from the active suppression of the host defense system by parasite-derived molecules (Asai, Shirasu 2015)

When a parasite tries to establish within a new host, the host produces chemicals to suppress its growth. For example, sequestration of mangiferin from Mangifera indica to Dendrophthoe falcata was observed to occur in the initial stages of infection as an initial host defense mechanism in response to the biotic stress caused by parasite, and these host defense molecules were found to be further utilized by the parasite as host recognition cues (Jadhav et al. 2005). Deposition of phenolic compounds by host plants often leads to the arrest of invasion of parasite, leading to necrosis of the parasite's invading tissue (Swarbrick et al. 2008; Yohida, Shirasu, 2009). In such cases, the parasites must co-evolve to counteract their hosts by transferring their own secondary metabolites or similar compounds, which reduce the host fitness. Most of these compounds

Table 8. Compounds identified as parasitic in origin. Compound indicated by $\sqrt{ }$ symbol obtained in the respective accession of $H$. elasticus. ${ }^{*}$ Marker compounds ${ }^{* *}$ Assisted marker compounds

\begin{tabular}{|c|c|c|c|c|c|c|c|}
\hline No. & Compound & HEN & HEH & HEC & HES & HEA & HEM \\
\hline 1 & 1,2,3-Benzenetriol* & $\sqrt{ }$ & $\sqrt{ }$ & $\sqrt{ }$ & $\sqrt{ }$ & $\sqrt{ }$ & $\sqrt{ }$ \\
\hline 2 & Methyl-3,4,5-trihydroxybenzoate & $\sqrt{ }$ & $\sqrt{ }$ & $\sqrt{ }$ & $\sqrt{ }$ & $\sqrt{ }$ & $\sqrt{ }$ \\
\hline 3 & 1,3,4,5-Tetrahydroxy-cyclohexanecarboxylic acid ${ }^{* *}$ & & $\sqrt{ }$ & $\sqrt{ }$ & $\sqrt{ }$ & $\sqrt{ }$ & $\sqrt{ }$ \\
\hline 4 & 1,2 -Benzenediol ${ }^{\star *}$ & $\sqrt{ }$ & $\sqrt{ }$ & & $\sqrt{ }$ & & $\sqrt{ }$ \\
\hline 5 & Hexadecanoic acid ${ }^{* *}$ & & $\sqrt{ }$ & $\sqrt{ }$ & $\sqrt{ }$ & & $\sqrt{ }$ \\
\hline 6 & 2,3-Dihydro-3,5-dihydroxy-6-methyl-4h-pyran-4-one ${ }^{* *}$ & & $\sqrt{ }$ & $\sqrt{ }$ & & $\sqrt{ }$ & $\sqrt{ }$ \\
\hline 7 & Hexadecanoic acid, methyl ester & $\sqrt{ }$ & $\sqrt{ }$ & $\sqrt{ }$ & & & \\
\hline 8 & Tetradecanoic acid, 12-methyl-, methyl ester & & $\sqrt{ }$ & & $\sqrt{ }$ & & \\
\hline 9 & Nonanoic acid, methyl ester & $\sqrt{ }$ & $\sqrt{ }$ & & & & \\
\hline 10 & Butanoic acid & $\sqrt{ }$ & & & & & $\sqrt{ }$ \\
\hline 11 & 1-Butanol, 3-methyl- & $\sqrt{ }$ & $\sqrt{ }$ & & & & \\
\hline 12 & Methyl5-oxo-2-pyrrolidinecarboxylate & & & $\sqrt{ }$ & & & $\sqrt{ }$ \\
\hline 13 & $\begin{array}{l}\text { 2,5-Cyclohexadiene-1,4-dione, compaund with } \\
\text { 1,4-benzenediol }\end{array}$ & & & & $\sqrt{ }$ & $\sqrt{ }$ & \\
\hline
\end{tabular}


have such a role in $H$. elasticus when infecting a host. The compounds 1,2-benezenediol, hexadecanoic acid and 2,3-dihydro-3,5-dihydroxy-6-methyl-4H-pyran-4-one can be considered as assisted markers of methanolic extract of $H$. elasticus, because the presence of these compounds was influenced by specific hosts only and their occurrence could not be confirmed in all the samples of parasite. The remaining seven compounds might be of parasitic origin alone, but their presence in the parasitic accessions depends on the host plant species. Most of the studied host trees might have suppressed the production of these compounds within the parasite. In Cuscuta reflexa, steroid properties and their amount were observed to differ during its establishment in Momordica (Takeshi et al. 2016). The life cycle of parasite weed is closely regulated by their hosts and the secondary metabolites produced by the hosts also playing an important role this interactions (Harro et al. 2003).

The parasite (H. elasticus) growing on different host plants produced different types of chemicals other than the major and assisted marker compounds and this clearly shows that the host had a significant influence on the phytochemical production of the parasite. Moreover, the UPGMA tree placed the hemi-parasitic accessions in various clusters, which clearly indicates the host effect on phytochemical production of the parasite. Except for the peak observed in marker compounds, the chromatograms and the number of compounds eluted differed among samples of $H$. elasticus, showing the effect of the host. This might occur during the preliminary infection stage or after the establishment of parasite within the host and the effect of the host on the parasite altered the metabolic pathways of the parasite, resulting in the production of variable chromatograms with a large number of significant chemicals within the parasite.

\section{Conclusions}

The work demonstrated that $H$. elasticus accessions collected from six different hosts that even though the parasite was of the same species, the production of chemical compounds could be altered by the influence of the host. Six accessions showed varied composition of compounds, in which 1,2,-benzenetriol and methyl-3,4,5-trihydroxybenzoate can be recognized as the marker compounds in the methanolic extract of $H$. elasticus. Along with these compounds, some are assisted marker compounds of this plant, whose occurrence and abundance are greatly affected by the host plant. The parasite growing in specific hosts can contain a greater number of therapeutically important chemicals. The UPGMA comparison of the studied accessions revealed host and H. elasticus covolution, which may lead to hostdirected speciation in this mistletoe. A phytochemical mosaicism are apparently visible in this hemi-parasitic plant emerged as a result of mistletoe-host interactions.
Therefore, when making preparations of a drug from the extracts, decoctions or powder of this parasitic plant, prime importance should be given to the host plant from which it was harvested or obtained. Comprehensive understanding of the chemical makeup and pro-health features of this species could lead to its use in a variety of medical disciplines as a spectacular product for treating a variety of human maladies.

\section{Acknowledgements}

We would like to express our sincere gratitude to all the staff of Department of Non timber products, Kerala Forest Research Institute, Thrissur, Kerala, India for providing the lab facilities for doing the analysis. This work did not receive any financial assistance from any of the funding agencies. All the authors declare that they have no interest conflict.

\section{References}

Ajith Kumar T.G., Mathew L. 2020. A short survey for new hosts of Helicanthes elastica (Desr.) Danser and its morphological diversity on selected hosts. Indian For. 146: 143-147.

Asai S., Shirasu K. 2015. Plant cells under siege: plant immune system versus pathogen effectors. Curr. Opin. Plant Biol. 28:18.

Bais N., Kakkar A. 2013. Comparative phytochemical analysis of Cuscuta reflexa parasite grown on Cassia fistula and Ficus benghalensis by GC-MS. Int. J. Pharm. Pharm. Sci. 5: 350-355.

Bais N., Kakkar A. 2014. Phytochemical analysis of methanolic extract of Cuscuta reflexa grown on Cassia fistula and Ficus benghalensis by GC-MS. Int. J. Pharm. Sci. Rev. Res. 25: 33-36.

Barlow B.A., Hawksworth F.G., Kuijt J., Polhill R.M., Wiens D. 1989. Genera of mistletoes. The Golden Bough 11: 1-4.

Betz J.M., Gay M.L., Mossoba M.M. Adams S., Portz B.S. 1997. Chiral gas chromatographic determination of ephedrine-type alkaloids in dietary supplements containing Ma Huang. J. AOAC Int. 80: 303-315.

Bouwmeester H.J., Matusova R., Sun Z., Beale M.H. 2003. Secondary metabolite signalling in host-parasitic plant interactions. Curr. Opin. Plant Biol. 6: 358-364.

Calder D.M., Lennox F.G., Bernhardt. 1982. Natural hybridazation between Amyema pendulum and Amyema quandang, Loranthaceae. Austr. J. Bot. 30: 625-633.

Cavar S., Zwanenburg B., Tarkow P. 2015. Strigolactones: occurrence, structure, and biological activity in the rhizosphere. Phytochem. Rev. 14: 691-711.

Chandrakasan L., Neelamegam R. 2011a. GC-MS analysis of Loranthus longiflorus Desr (a hemi-parasite) bark harvested from two host trees. J. Pharm. Res. 4: 3072-3074.

Chandrakasan L., Neelamegam R. 2011b. In vitro studies on antioxidants and free radical scavenging activities in the extracts of Loranthus longiflorus Desr bark samples obtained from two host trees. J. Phytol. 3: 22-30.

Chang M., Lynn D.G. 1986. The haustorium and the chemistry of host recognition in parasitic angiosperms. J. Chem. Ecol. 12:561-579

Clarke C.R., Timko M.P., Yoder J.I., Axtell M.J., Westwood J.H. 2019. Molecular dialog between parasitic plants and their hosts. Annu. Rev. Phytopathol. 57: 279-99.

Franklin U.O., Wintola O.A., Afolayan A.J. 2017. 
Micromorphological studies of the Loranthaceae, Phragmanthera capitata (Sprengel) Balle. J. Bot. 2017: 5603140.

Furuhashi T., Nakamura T., Iwase K. 2016. Analysis of metabolites in stem parasitic plant interactions: interaction of CuscutaMomordica versus Cassytha-Ipomoea. Plants 5: 1-14.

Gamble J.S. 1967. The Flora of the Presidency of Madras. $2^{\text {nd }} \mathrm{Ed}$. Botanical Survey of India, Culcutta, pp. 873-878.

Indrani N., Balasubhramanian K. 1985. Chemical examination of Dendrophthoe falcata growing on Terminalia tomentosa. Leather Sci. 32: 206

Jadhav R.B., Anarthe S.J., Surana S.J., Gokhale S.B. 2005. Hosthemiparasite transfer of the C-glucosyl xanthone mangiferin between Mangifera indica and Dendrophthoe falcata. J. Plant Interact. 1: 171-177.

Jain S K. 1965. Medicinal Plantlore of the tribals of Baster. Econ. Bot. 19: 236-250.

Jamison D.S., Yoder J.I. 2001. Heritable variation in quinine induced haustorium development in the parasitic plant Triphysaria. Plant Physiol. 125: 1870-1880.

Kim D., Kocz R., Boone L., W. Keyes J., Lynn D.G.1998. On becoming a parasite: evaluating the role of wall oxidases in parasitic plant development. Chem. Biol. 5: 103-117.

Lynn D.G., Chang M.1990. Phenolic signals in cohabitation: implications for plant development. Annu. Rev. Plant Physiol. Plant Mol. Biol. 41: 497-526.

Manickam D., Periyasamy L. 2014. GC-MS analysis of methanol extract of Decalepis hamiltonii root (Wight and Arn). World J. Pharm. Pharm. Sci. 3: 983-989.

Namboothiri K.R.R. 2011. Albutha Oushadha Chedikal. $5^{\text {th }}$ Ed. H\&C Pubishing House, Thrissur.

Nayar T.S., Rasiya Beegum A., Mohanan N., Rajkumar G., Sibi, M. 2006. Flowering Plants of Kerala: A Handbook. Tropical botanic garden and research institute, Palode, Thiruvanathapuram.

Okubamichael D.Y., Griffiths M.E., Ward D. 2017. Host specificity in parasitic plants - perspectives from mistletoes. AoB Plants 8: plw069.

Piwowarczyk R., Ochmian I., Lachowicz S., Kapusta I., Sotek Z., Blaszak B. 2020. Phytochemical parasite-host relations and interactions: A Cistanche armena case study. Sci. Total Environ. 716:1-11

Press M.C., Graves J. 1995. Parasitic Plants. Chapman and Hall, London, UK.

Rai D.K., Sharma V., Pal K., Gupta R. 2016. Comparative phytochemical analysis of Cuscuta reflexa Roxb parasite grown on North India by GC-MS. Trop. Plant Res. 3: 428-433.

Rajasekaran K. 2007. Studies in Indian Loranthaceae VIIIInflorescence. J. Econ. Taxon. Bot. 31: 177-180.

Sasidharan N., Sivarajan V.V. 1996. Flowering plants of Thrissur forest (Western Ghats, Kerala, India). Scientific Publishers. Jodhpur, pp. 385.
Saucet S.B ., Shirasu K. 2016. Molecular parasitic plant-host interactions. PLoS Pathol. 12: 1-6.

Scot G.J. 1871. Loranthaceae - the mistletoe order germination and mode of attachment. J. Agr. Hort. Soc. India 2: 257

Shanavaskhan A.E., Sivadasan M., Ahmed H., Alfarhan, M.,Thomas, J. 2012. Ethnomedicinal aspects of angiospermic parasites and epiphytes of Kerala India. Indian J. Tradit. Knowl. 11: 250-258.

Shanavaskhan A.E., Sivadasan M. 2009. Epiphytes and Parasites of Kerala India. $1^{\text {st }}$ Ed. Bihen Singh Mahendrapal Singh, Dehradun, pp. 213-272.

Stermitz F.R., Harris G.H. 1987. Transfer of pyrrolizidine and quinolizidine alkaloids to Castilleja (Scrophulariaceae) hemiparasites from composite and legume host plants. J. Chem. Ecol. 13: 1917-1925.

Sunil Kumar K.N., Saraswathy A., Amerjothy S. 2015. Survey report on hosts and haustoria of Helicanthes elastica (Desr.) Danser in Udupi and Dakshina Kannada districts of Karnataka and Kasargod district of Kerala, India - A concise review plus some new additions. Indian For. 141: 448-451.

Swarbrick P.J., Huang K., Liu G., Slate J., Press M.C., Scholes J.D. 2008. Global patterns of gene expression in rice cultivars undergoing a susceptible or resistant interaction with the parasitic plant Striga hermonthica. New Phytol. 179:515-529

Thomas S., Melnyk C.W., Wakatake T., Zhang J. Sakamoto Y., Kiba T., Yoshida S., Matsunaga S., Sakakibara H., Shirasu K. 2017. Interspecies hormonal control of host root morphology by parasitic plants. Proc. Natl. Acad. Sci. USA 114: 5283-5288.

Thriveni M.C. 2013. Studies on Loranthaceae and Viscaceae of Karnataka. PhD Thesis. University of Mysore.

Tomilov A., Tomilova N., Shin D., Jamison D., Torres M., Reagan R., McGray H., Horning T., Truong R., Nava A., Yoder J. 2006. Chemical signalling between plants: mechanistic similarities between phytotoxic allelopathy and host recognition byparasitic plants. In: Dicke M., Takken W. (Eds.) Chemical Ecology: from Gene to Ecosystem. Springer, Dordrecht, pp. 55-69.

Warrier P.K., Nambiar V.P., Ramankutty C. 1996. Indian Medicinal Plants. Orient Longman, Madras.

Watson D.M. 2001. Mistletoe: a keystone resource in forests and woodlands worldwide. Annu. Rev. Ecol. Syst. 32: 219-249.

Wilson C.A., Calvin C.L. 2006. An origin of aerial branch parasitism in the mistletoe family, Loranthaceae. Am. J. Bot. 93: 787-796.

Xie X., Yoneyama K., Yoneyama K. 2010. The Strigolactone story. Annu. Rev. Phytopathol. 48: 93-117.

Yoshida S., Shirasu K. 2009. Multiple layers of incompatibility to the parasitic witchweed, Striga hermonthica. New Phytol. 183:180-189. 